\title{
RESEARCH ON PRODUCT INNOVATIVE DESIGN METHOD DRIVEN BY CLIENT DEMANDS
}

\author{
Limin Li, Guiqin Li, Shi'an Huang \\ Center of CIMS and Robotics,Shanghai University,Shanghai 200072 P.R.China,Email: \\ leeching@staff.shu.edu.cn
}

\begin{abstract}
Based on the research on acquiring methods of client demands for product innovation development, apply system cluster analyses in modeling demands. In study of foundation of QFD and TRIZ, an integration process model is put forward for product innovation design of QFD and TRIZ. The model is developed taking in the advantages of both, which respond to client demands information effectively. The whole process is set up in structure and regularization, according with general process of human innovative thinking. And it has strong maneuverability as well.
\end{abstract}

Key words: client demands, innovative design, QFD, TRIZ, integrated model

\section{INTRODUCTION}

Nowadays, "to treat the customers as the core, rapid response to the markets, and to satisfy the client's requirements with might and main" has been the main intention to enhance the competition ability of the enterprises. Since product innovation has been hardly indifferent for the survival and developing of the manufacture enterprises, to seek an effective design theory which is suitable for our nation's status and with it to design the products which can satisfy the client's demands as well as to realize the technique and product innovation are popular in design field. Therefore, based on the principle that client's demand is the motivation of the new products innovation and with the advantages in products design of the QFD (Quality

Please use the following format when citing this chapter:

Li, Limin, Li, Guiqin, Huang, Shi'an, 2006, in International Federation for Information Processing (IFIP), Volume 207, Knowledge Enterprise: Intelligent Strategies In Product Design, Manufacturing, and Management, eds. K. Wang, Kovacs G., Wozny M., Fang M., (Boston: Springer), pp. 433-439. 
Function Deployment) and TRIZ (Theory of Inventive Problem Solving), a product innovation model driven by client's demands is put forward.

\section{ACQUIREMENT AND ANALYSIS METHODS OF CLIENT'S DEMANDS}

\subsection{Methods to acquire client's demand}

No matter the idea of a new project come from the exterior or interior of an enterprise, the enterprise should take market survey and analyses it with the consideration of its competitiveness and its products ability. The person related with the new project should be clear on two things: who were the clients and which kind of the client's demands we should satisfy.

There are several methods to confirm client's demands: Designers themselves act as users; consumer survey; Organize different users to take part in some special discussion; Talk to the users face to face; Inspect the products in real life; research the competitor's products. Summarize the user's feedback and suggestions. As the web technology is developing, to survey on the internet having a good performance as well.

The most difficulty of the market research is how to dig the client's potential demands. For technique evolution theory can not only forecast technology development, but also exhibit the realization of conceivable product structure. It takes on directive effect for product innovation design. Directed Evolution is the branch of the technique revolution theory which core is the management with control process and technology evolution. The theory has been figured it out there are 10 modes for the product evolution. Under each mode there are many evolution ways. With the application of the modes and the evolution ways, the designers can generate the initial idea of product innovation. Apply the technique evolution theory to forecast the development directions of product, and then translate those directions into client's words, farther to dig up and induce client's potential demands combined with the market survey methods.

\subsection{Analysis methods of client demands}

Applying the Hierarchical clustering method to neaten of the client demands, we could acquire a relatively objective quantitative tool for the personnel participate in product development project to sort the scattered client demands.

1. Set up a demands matrix with the data from the market research 


$$
X=\left[\begin{array}{cccc}
x_{11} & x_{12} & \cdots & x_{1 p} \\
x_{21} & x_{22} & \cdots & x_{2 p} \\
\vdots & \vdots & \vdots & \vdots \\
x_{n 1} & x_{n 2} & \cdots & x_{n p}
\end{array}\right]
$$

To eliminate the influence of the dimension, normally transform the row vectors, that is

$$
x_{i j}{ }^{\prime}=\left(x_{i j}-\bar{x}_{j}\right) / S_{j}
$$

in which: $\bar{x}_{j}=\frac{1}{n} \sum_{i=1}^{n} x_{i j} ; S_{j}{ }^{2}=\frac{1}{n-1} \sum_{i=1}^{n}\left(x_{i j}-\bar{x}_{j}\right)^{2}$

2.Comparability measurement. Measure the distance between client demands with Euclidian distance.

$$
d_{i j}=\left[\sum_{k=1}^{p}\left(x_{i k}-x_{j k}\right)^{2}\right]^{1 / 2}
$$

3.To use square-sum subtraction, the basic idea root in squared difference analyses. If sort $n$ items of client demands into $k$ groups, $G_{1}, G_{2}, \cdots, G_{k}, x_{i t}$ denote the $i$ item of client demands in $G_{t}, n_{t}$ denotes the number of the items in $G_{t}, \bar{x}_{t}$ is the $\mathrm{cg}$ of $G_{t}$, then the square-sum subtraction in cluster $G_{t}$ is

$$
S_{t}=\sum_{i=1}^{n_{t}}\left(x_{i t}-\bar{x}_{t}\right)^{\prime}\left(x_{i t}-\bar{x}_{t}\right)
$$

The entire square-sum in groups is

$$
S=\sum_{t=1}^{k} \sum_{i=1}^{n_{t}}\left(x_{i t}-\vec{x}_{t}\right)^{\prime}\left(x_{i t}-\bar{x}_{t}\right)=\sum_{t=1}^{k} S_{t}
$$

First put $n$ items of demands as one group respectively, and reduce one cluster every time, each time the square-sum subtraction will augment, 
combine two groups to make augment of $\mathrm{S}$ least, till all groups turn to one group.

4. Draw a dendriform pedigree chart of above cluster operation result. Thus the congregate process and distance of each group can be visually made out. Ascertain the groups collective based on the need of analyses and disposal next step.

\section{INNOVATIVE DESIGN ORIENTED QFD AND TRIZ INTEGRATED PROCESS MODEL}

QFD can effectively transform the client demands into technical requirements of engineering designers via the quality house, and it has great advantages in acquiring information. The quantitative description and evaluation for functions, will administer to widen the ideas of plan and to grab the key and the essential of the problems. TRIZ theory has a set of comparatively integrant system info in solving the conflicts in product design, and it has a powerful logic strictness and operation procedure. Furthermore, TRIZ has regularity cognition at the human's inventive process, which is coherent with the human's learning process that is studied in cognition psychology. Thus, based on the advantages of TRIZ in eliminating conflict, and integrate the theories and methods of QFD, and then combined with substance field analyses, educe the process model for innovative design as shown in the fig.2.

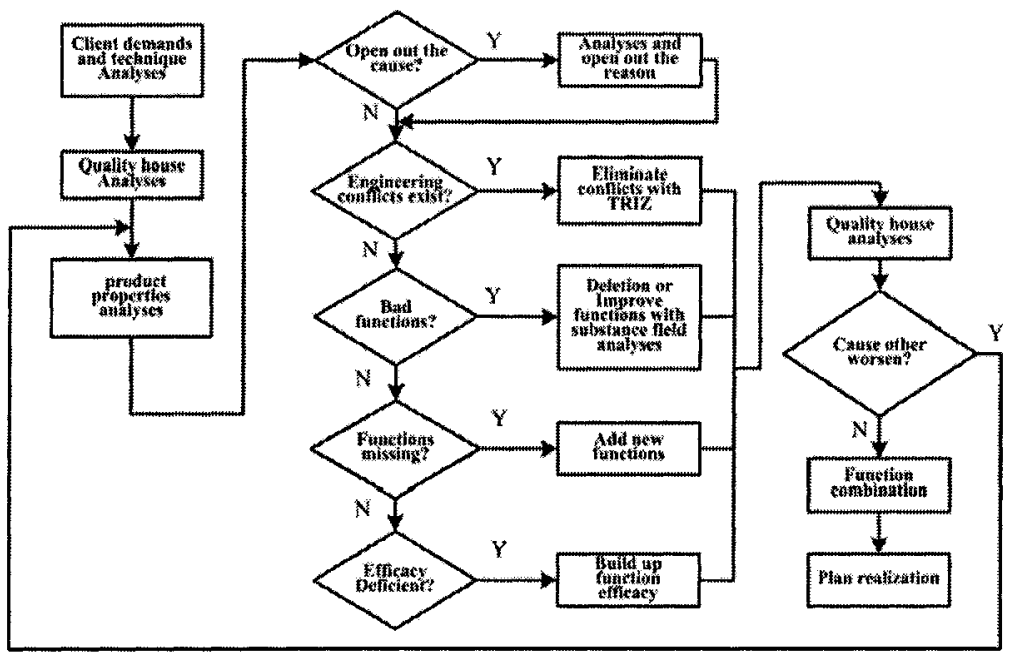

Fig. 2 the process model of solving problem using integrated QFD and TRIZ

We can accomplish the innovative design with this process model in several steps: 
1) Based on the analysis of client demands and product functions, we should firstly set up the quality house from the requirement to product properties and functions, transform "languages of client demands" to "languages of engineering design", and, according to the analyses tools DFD provided and analysis product properties, find out the negative correlative guideline, namely design conflicts. Choose the negative correlative guideline and issue function as the key to be solved next step.

2) Classify the design conflicts, make sure the negative correlative are caused by the engineering conflicts or the disability of self-function, and then utilize the corresponding tools showed in fig. 1 to consummate the functions, eliminate the technical or physical conflicts.

3) During eliminating the conflicts and consummating, the basic functions may simultaneously worsen other functions, which will cause new conflicts, so re-analyses with the quality house should be taken after step 2 , to judge whether new problems have been caused till designer satisfaction.

4) Synthesize the improved accession function with the other functional structures, and then the feasible collective design plan can be produced.

\section{APPLICATION EXAMPLES}

The development of the vacuum infuse equipments is a greatly benefit from the method in this investigation. The quality house constructed by the requirements and technical properties is showed in fig. 3.

Then, apply the method of eliminating conflict to solving the conflict between airproof and unlock of the airproof gate.

There is two main functions for the airproof gate of the vacuum infuse equipments: providing alleyway for mould raw material; airproofing to form vacuum field. It has a high frequency of open and close, and it should have a press distortion beforehand if the elasticity rubber airproof action based on airproof principles. If the distortion is strong, the airproof effect will has a good performance, but a strong distortion with a high pressure will decrease the open close performance. If the distortion is weak, the elasticity airproof piece distort after press, thus the gate and ream pivot will bear the force, the gate body will be distorted or a period of time action to decrease the performance of the airproof. Substance field model is showed in fig.4. The technical conflicts described by the 39 standard parameters of TRIZ as follows:

- The predicted parameter improvement: the reliability of equipment.

- Technical attrition parameter: maneuverability. 


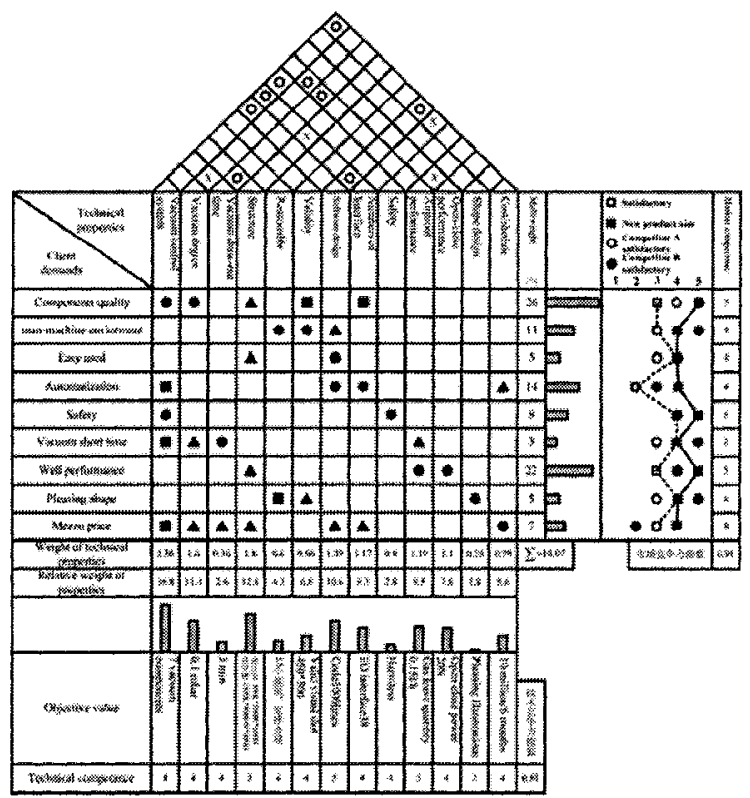

Fig. 3 the quality house constructed by requirement and technique properties

Checked from the conflicts resolve matrix, the usable principle to solve the conflicts constituted with reliability and maneuverability of equipment are the principles of $27 \mathrm{th}, 17$ th and 40th. Finally we find the first cue from principle of 17th (change dimension): change the moved or rest object from one dimension space to two dimension space, and change the object in two dimension space to three dimension space. It provided a remarkable idea for the improvement of the airproof gate.

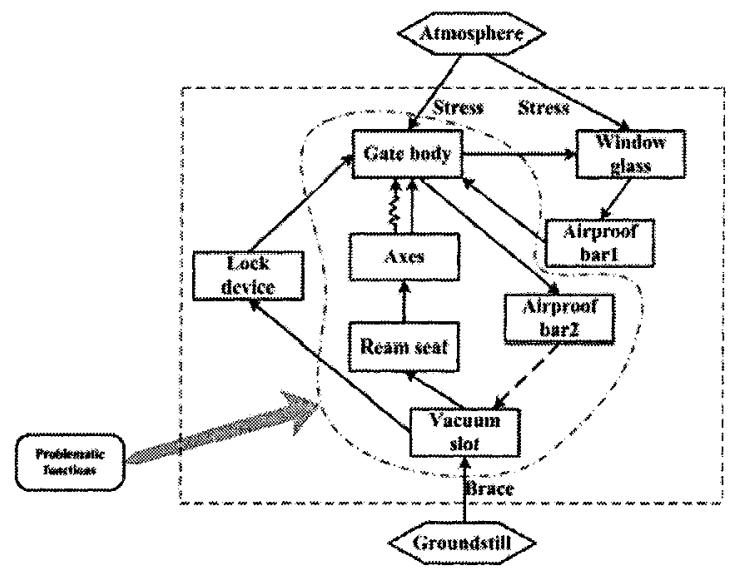

Fig. 4 substance field model of airproof gate system 
Demands

According to the cue, adopt the first principle alter the gate originally in the space only rotate the reamer pivot with the circular rotation. But being transformed to be the whole gate body rotates through the reamer pivot along the force direction after being pressed. In the real life application, change the reamer pivot structure, as a clearance conjugate during rotating, and keeping a $3 \mathrm{~mm}$ abundant capacity between the hole and the pivot (fig. 8 shows the conjugate instance after gate close) to ensure that move with the gate when being pressed. The gate will not be affected by torque action.

The practice result proves the design eliminate the conflicts between the performance of airproof and open-close effectively.

\section{CONCLUSIONS}

With the client demands as the driven force of the product innovation, we can guarantee the client satisfaction during product design process and reduce the risks of products development. Utilizing the structural model integrated by QFD and TRIZ, we settle the malpractice of lack in solving problems by QDF, and avoid the "two layer questions" caused by simply using TRIZ, and effectively transform the client demands into engineering realization.

\section{REFERENCE}

1. Rogers Beth, Creating Product Strategies (Northeast Finance and Economics University Press, 2003)

2. Tan Runhua, Progress of some problems in product design for innovation, Chinese journal of mechanical engineering, 39(9), 11-16(2003)

3. Mei Changlin, Zhou Jialiang, Practical Statistics Technique (Science Press, 2002)

4. Hu Qinxi, Yu Tao, Fang Minlun, Principle and Application of Parallel Engineering (Shanghai University Press, 2001)

5. Cristiano J, Liker J K, White Chelsea C. Customer-Driven Product Development Through Quality Function Deployment in the U.S. and Japan. $J$ PROD INNOV $M A N A G,(17)$, P286-308(2000)

6. Sushkov V V, Mars N J, Wognum P. Introduction to TIPS: a theory for creative design. Artificial Intelligence in Engineering, (9): P177-189(1995) 